Effect evaluation of a road safety education program based on victim testimonials in high schools in Belgium

Peer-reviewed author version

CUENEN, Ariane; BRIJS, Kris; BRIJS, Tom; VAN VLIERDEN, Karin; DANIELS, Stijn \& WETS, Geert (2016) Effect evaluation of a road safety education program based on victim testimonials in high schools in Belgium. In: Accident Analysis and Prevention, 94, p. 18-27.

DOI: 10.1016/j.aap.2016.05.006

Handle: http://hdl.handle.net/1942/22535 


\title{
Effect evaluation of a road safety education program based on victim testimonials in high schools in Belgium.
}

\author{
Ariane Cuenen ${ }^{1 *}$, Kris Brijs ${ }^{1}{ }^{2}$, Tom Brijs ${ }^{1}$, Karin Van Vlierden ${ }^{1}$, Stijn Daniels ${ }^{1}$, Geert Wets ${ }^{1}$ \\ 1 Transportation Research Institute (IMOB), Hasselt University, Diepenbeek 3590, Belgium \\ ${ }^{2}$ Faculty of Applied Engineering Sciences, Hasselt University, Diepenbeek 3590, Belgium \\ * Corresponding author. \\ E-mail address: ariane.cuenen@ uhasselt.be \\ Telephone number: +32(0) 11269108
}

\begin{abstract}
For several decades policy makers worldwide have experimented with testimonials as a strategy to promote road safety supportive views in a wide variety of target populations such as recidivists and students. In its basic format, a (relative of) a victim or an offender brings a personal testimonial of what it is to experience a traffic accident. The underlying idea is that such a testimonial will emotionally affect participants, thereby stimulating them to cognitively reflect upon their own behavior and responsibility as a road user. Unfortunately, empirical literature on the effectiveness of this strategy is rather scarce and inconsistent. This study investigated the effect of a large-scale program with victim testimonials for high schools in Belgium on five sociocognitive and behavioral variables drawn from the Theory of Planned Behavior (i.e., attitude, subjective norm, perceived behavioral control, behavioral intention and behavior). Moreover, this study investigated program effects on participants' cognitive and emotional estate and whether this influences the program's impact on socio-cognitive and behavioral variables. Our test sample included 1,362 students, who were assigned to a baseline - follow-up group and a post-test - follow-up group. We questioned both groups, a first time (just before or after session attendance) on paper, and a second time (two months after session attendance) online. Results indicate the program had, both immediate and two months after attendance, small to medium positive effects on most socio-cognitive and behavioral variables. However, effects depended on participants' demographic profile, their baseline values on the sociocognitive and behavioral variables, and the degree to which they were cognitively/emotionally affected by the program. We discuss the practical implications of these findings and formulate recommendations for the development of future interventions based on victim testimonials.
\end{abstract}

Victim testimonials; Theory of Planned Behavior; Effect Evaluation; Pre-Driver Education 


\section{Introduction}

\subsection{The use of victim testimonials as an intervention strategy}

Testimonials by (relatives of) people who were involved in a traffic accident are frequently used in order to sensitize people to behave safely in traffic. The underlying idea is that such a testimonial will emotionally affect participants, thereby stimulating them to cognitively reflect upon their own behavior and responsibility as a road user. Over the years, victim testimonials came in use worldwide as a safety promoting intervention strategy. Even though the basic format is always roughly the same, there are differences in terms of which populations are targeted as program participants and how such a testimonial is implemented. Concerning the populations being targeted, while some initiatives are aimed at traffic offenders, others focus primarily at learner drivers or high school students. As mentioned, there is variation in the implementation too. While in some cases testimonials are brought by (relatives of) victims of a traffic accident, others are delivered by offenders. What also differs in the program implementation, is the emotional mechanism to be induced by a testimonial. For instance, some programs clearly focus on the arousal of negative risk-aversive emotions such as threat, worry, guilt, or anticipated regret, while other initiatives are rather aimed at evoking positive emotions such as sympathy or respect for the victims. Another varying aspect related to the implementation of such victim testimonials is the medium used to bring the message to program participants. These range from mass media like television spots (such as in Sweden; Linderholm, 2000) to more interactive formats such as road shows (e.g., "Never saw the day" in Ireland, O'Brien et al., 2002; "Being dead isn't cool" in Norway, Moan and Ulleberg, 2007; and "Too much punch for Judy" in Scotland, Powney et al., 1995), and discussion groups in a classroom setting, which is the most popular format.

The use of victim testimonials originates from the United States where in 1982 an initiative called 'Mothers Against Drunk Driving' (MADD) was organized. The MADD program used testimonials of (relatives of) drunk-driving victims to sensitize Driving Under the Influence (DUI) recidivists in the hope to reduce alcohol-related fatalities. These victim testimonials were meant to operate as a therapeutic experience for the victims and an opportunity for convicted DUI drivers to understand the injuries that their behavior can inflict upon other road users (Shinar and Compton, 1995). Later, several equivalent programs were set up in other countries. However, the focus shifted from DUI drivers to high school students (Feenstra et al., 2014; Glendon et al., 2014; King et al., 2008; Poulter and McKenna, 2010; Rosenbloom et al., 2009; Twisk et al., 2014) and learner drivers (Pfeiffer et al., 2006). Despite the rising popularity of victim testimonials, there is not that much empirical research available on the effectiveness of this method. Most of the evaluation studies applying to victim testimonials are done with the help of a questionnaire (Feenstra et al., 2014, King et al., 2008; Pfeiffer et al., 2006; Pollacsek et al., 2001; Poulter and McKenna, 2010; Rosenbloom et al., 2009; Twisk et al., 2014). The empirical literature available on the effectiveness of victim testimonials contains mixed results and therefore remains inconclusive. While some studies find positive effects (Feenstra et al., 2014; King et al., 2008; Pfeiffer et al., 2006; Poulter and McKenna, 2010; Rosenbloom et al., 2009; Shinar and Compton, 1995; Twisk et al., 2014), others fail to do so (Glendon et al., 2014; Polacsek et al., 2001; Shinar and Compton, 1995; Twisk et al., 2014) or even report negative effects (Feenstra et al., 2014; Glendon et al., 2014; Poulter and McKenna, 2010). As a consequence, for academics as well as for policy makers and practitioners, this is a research topic that requires further attention. 


\subsection{Aims of the study}

The aim of the study was to empirically evaluate the effectiveness of the Flemish schoolbased road safety education program 'Traffic Informers'. We decided to evaluate the effectiveness on socio-cognitive and behavioral variables from the Theory of Planned Behavior (TPB, Ajzen, 1985). Our decision to do so was not only based on the acknowledged predictive validity of the variables appearing in the TPB-model (e.g., Conner et al., 2007; Elliott et al., 2007; Elliott et al., 2013), but also on a careful analysis of the program's targeted objectives as they were formulated in preliminary discussions with the program developers. In addition, several evaluation studies applying to victim testimonials were done by means of a TPB-based questionnaire (Feenstra et al., 2014; Poulter and McKenna, 2010; Rosenbloom, et al., 2009). The TPB is one of the empirically most supported behavioral theories and has been validated in diverse research domains (Godin and Kok, 1996; Stutton, 1998). The theory postulates that behavioral intention (i.e., a person's expression of support for the behaviors under study), the most proximal determinant of behavior, is determined by three conceptually independent variables: (1) attitude (i.e., the expression of (dis)favor towards the behaviors under study), (2) subjective norm (i.e., perceived social expectations about the behaviors under study), and (3) Perceived Behavioral Control (PBC, i.e., the subjective probability that a person is capable of executing (or not) the behaviors under study).

Altogether this study aimed to answer the following four specific research questions. First of all: 'Is there an immediate effect of the program on socio-cognitive and behavioral variables (i.e., attitude, subjective norm, PBC, behavioral intention and behavior)?'. Secondly: 'Is there an effect of the program on socio-cognitive and behavioral variables two months after session attendance?'. Thirdly: 'Does the program have an immediate effect on participants' cognitive and emotional estate?'. Finally: 'Does the program's immediate effect on participants' cognitive and emotional estate influence the program's impact on sociocognitive and behavioral variables?'.

\section{Methodology}

\subsection{Traffic Informers}

Traffic Informers is a large-scale school-based road safety education program that runs in the Flemish speaking part of Belgium. The first edition of the program was held in 2012-2013 with a total of 14,763 students attending a session. The program is organized by a non-profit organization (i.e., 'Rondpunt') and is subsidized by the Flemish Ministry of Transportation and Public Works. The program targets (male and female) 16-17 year old high school students of three education types (i.e., general, technical and occupational). General education, sometimes called transition education, prepares students for university. The education is focused on theory and general knowledge. Technical education like general education, offers a theoretical education but includes also courses that are focused on practical experience. It prepares students both for university or a specific job or function. Occupational education as a rule prepares students for a specific job or function. This education is focused on practical experience. Although all these education types offer the possibility to go to university, students of occupational education need to follow an extra year of high school before they are allowed to go to university. The majority in this population does not have a driver license yet (in Belgium, a learner license can be obtained from the age of 16 years and nine months, while a permanent driver's license can be obtained only from the age of 18 years). As such, this program focuses primarily on pre-drivers and only marginally on young novice drivers. 
Schools that are interested in this program register through a website

(http://rondpunt.be/getuigen/61/) and give their preference in terms of time and location. The program costs 50 euro and takes two hours. There is an imposed maximum of 35 students per session. The first hour is dedicated to the testimonial of a (relative of a) traffic victim.

Informers talk about their life before the traffic accident, the circumstances of the accident itself and their life afterwards. During the second hour there is room for a group discussion. Students share their opinions and impressions with the informer and with each other. The program developers deliberately avoid a fear appeal-like style with bloody and excessively shocking pictures since there are indications that an over-fixation on the severity of the immediate 'physical' consequences of a traffic accident, will miss effect or even result in counterproductive effects (e.g., Carey et al., 2013; Peters et al., 2012; Ruiter et al., 2001; Ruiter et al., 2014; Ruiter et al., 2004; Witte, 1992). The informers adopt a serene rather than a sensational style and try to have an impact on participants not by means of emphasizing the most traumatic immediate consequences of the traffic accident but by elaborating on the longterm physical, emotional, social, financial and professional impact of such an event. In addition to that, informers pay special attention to the establishment of an empathetic connection with the group. The latter is done for instance, through a careful and detailed sketch of the informer's personal life before the traffic accident. Informers try to show participants that their life was basically not that different from theirs and that the situational circumstances of the traffic accident itself are perfectly imaginable instead of being exceptional. Also, they try to make participants aware of the fact that a traffic accident is never just a matter of bad luck, but rather a process of inappropriately coping with a complex of risk facilitating conditions and a matter of socially shared responsibility. Before becoming an actual informer, candidate-informers first receive a concise formal training in which the above mentioned principles are addressed and where they learn ways to bring a personal testimonial in a serene way. If necessary, a personal buddy accompanies the informer and assists during the sessions.

\subsection{Questionnaire development}

We developed a questionnaire consisting of three sections. The first section probed for demographic variables such as age, gender and education type. The second section contained a total of 55 items and was dedicated to socio-cognitive and behavioral variables. We addressed several types of (un)safe traffic behavior (e.g., using safety helmet, drink driving, speeding, crossing red lights) and questioned the following variables: Attitude (23 items, e.g., A safety helmet can prevent serious injuries), subjective norm (11 items, e.g., My parents find it good that I wear a safety belt), PBC (11 items, e.g., If I go to a party, I drink alcohol despite that I have to ride/bike to home), behavioral intention (5 items, e.g., I intend to take into account other road users) and behavior (5 items, e.g., Usually I do not exceed the speed limits). In the third section, 10 items were added to investigate the extent to which participants were inclined to respond in a socially desirable manner since this is a frequently mentioned potential response bias in the methodological literature on questionnaire surveys (e.g., af Wåhlberg, 2009; Harrison, 2010; Lajunen et al., 1997; Lajunen and Özkan, 2011; Paulhus, 1984; Paulhus and Reid, 1991). Socially desirable responding consists of two factors: (1) the tendency towards 'impression management' (i.e., the deliberate tendency to give favorable self-descriptions to others) and (2) the tendency towards 'self-deception' (i.e., a positively biased but subjectively honest self-description). The items were derived from the Driver Social Desirability Scale (DSDS) developed by Lajunen et al. (1997). Impression management was questioned with 5 items (e.g., I always keep sufficient distance between the driver in front of me and myself), as was self-deception (e.g., I always remain calm and 
rational in traffic). The final section of the questionnaire contained 8 items assessing the program's impact on participants' cognitive and emotional estate: 5 items measured cognitive program impact (e.g., The testimonial was useful) and 3 items assessed emotional program impact (e.g., The testimonial was shocking). Both the second and third section of the questionnaire used 5-point Likert scales going from 1 (totally agree) to 5 (totally disagree).

Before its final implementation, we first pilot tested the questionnaire. High school students $(\mathrm{N}=67)$ offered comments on the readability and clarity of the statements and the instructions. Only a few minor adjustments needed to be done.

\subsection{Design and procedure}

This study evaluated the program's first edition (September 2012 - June 2013). Because of the restricted time available for measurements, we were not able to use a fully controlled experimental design with random assignment and pre- and post-tests in both an experimental group and a control group. Therefore, we adopted a quasi experimental design wherein participants were assigned to a baseline - follow-up group or a post-test - follow-up group on the day of session attendance (Brijs et al., 2014). Both groups completed a questionnaire twice with a two months gap in between. As illustrated in Figure 1, the baseline - follow-up group received the questionnaire before the program session and two months after attendance. The post-test - follow-up group received the questionnaire immediately after and two months after the program session.

Although the design does not control for differences between the different groups on the socio-cognitive and behavioral variables, it does control for differences between the different groups on demographic variables. Moreover, it allows for testing immediate program effects by comparing scores between the first measurement in the baseline-follow-up group and the first measurement in the post-test - follow-up group, as in a post-test only design comparing a no program (control) group vs. a program group. Finally, it allows to test whether effects are present two months after session attendance, by comparing the scores between the first and second measurements within the baseline - follow-up group. Importantly, the design allows to investigate the presence of a repeated questionnaire exposure effect which can arise since people fill in the same questionnaire twice (Shadish et al., 2002).

The first measurement was on paper at the start (baseline - follow-up group) or at the end (post-test - follow-up group) of the program session somewhere between September 2012 and March 2013. The second measurement happened online two months after session attendance (in both groups) somewhere between November 2012 and May 2013.

The first measurement was an anonymous paper-and-pencil survey administered by a total of five trained data collectors who went to different locations across Flanders where program sessions were organized. They first shortly introduced the study to the students and asked formal consent together with contact information for participation to the second measurement. Next students completed the questionnaires. Taken together, the whole procedure took approximately 15 minutes. The second measurement was done by e-mail two months after the first measurement for both groups. Students received a link by means of which they could access an internet page containing the questionnaire. Filling in the online questionnaire took approximately 10 minutes. The online questionnaire contained exactly the same items as the questionnaire used at the first measurement, except for the items assessing the program's impact on participants' cognitive and emotional estate. This is simply because too much time elapsed between session attendance and the second measurement in order for participants to be able to make an accurate and reliable estimation of their cognitive and emotional estate at that point in time. 
Recruitment of students for the first measurement was as follows: The organizing nonprofit organization (i.e., Rondpunt) informed the research team about schools that registered for one or more sessions of Traffic Informers. These schools were contacted (by e-mail or a phone call) to invite them to participate in the study. Schools that were interested gave their preference for the timing of the measurement (i.e., just before or after the session), taking into account their internal time schedules (e.g., breaks, mandatory lessons). In case the measurement was before the session, students following that session automatically belonged to the baseline - follow-up group, while in case the measurement was after the session, students following that session automatically belonged to the post-test - follow-up group. Schools were kept unaware of the study's aim. In case schools did not express any preference as to the timing of the measurement, the research team randomly assigned the students to one of the two groups.

Recruitment of students for the second measurement was as follows: invitation messages were sent two months after session attendance (by e-mail or Short Message Service (SMS)) to students who left their contact details during the first measurement. Students received two reminder messages within the week after the invitation messages were sent.

Students who filled in both questionnaires (first and second measurement) could win one out of twenty film tickets or one out of three smart phones through a lottery where the experimenters randomly assigned the prizes to twenty-three students.

During the first measurement, 1,362 students filled in the questionnaire. Of these, 658 (48.30\%) belonged to the baseline - follow-up group, while $704(51.70 \%)$ belonged to the post-test - follow-up group. During the second measurement, 449 students completed the questionnaire. The data of 277 students could be matched with the data of the first measurement. Of these students, $136(49.10 \%)$ belonged to the baseline - follow-up group, while $141(50.90 \%)$ belonged to the post-test - follow-up group.

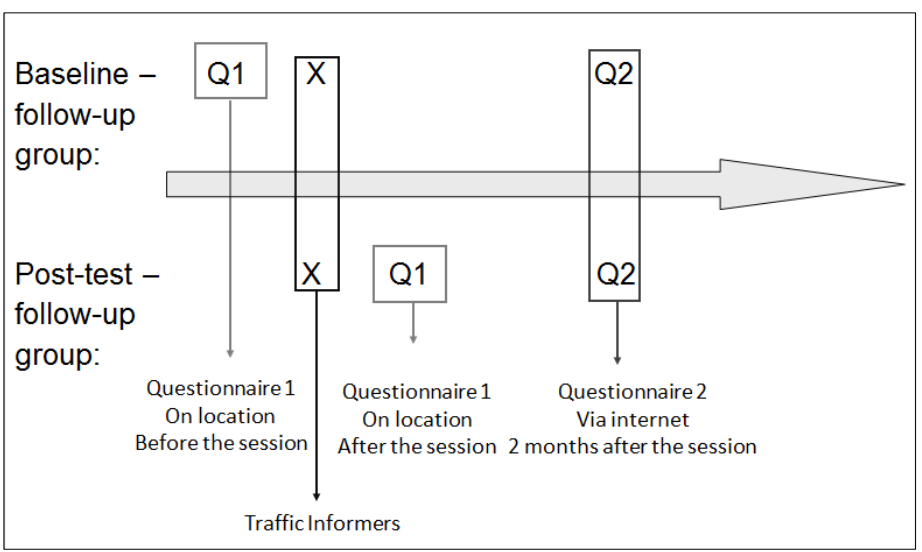

Figure 1. Design.

\subsection{Analyses}

The data was processed using SPSS (IBM Statistics 20). First, we recoded items dedicated to socio-cognitive and behavioral variables, so that lower scores always imply a more road safety supportive view. Then, we conducted reliability analyses to determine if the separate items could be averaged for the different variables. A Cronbach's alpha of .65 or higher was considered satisfactory for data clustering (Field, 2013). Test-retest reliability for the different variables was verified by checking statistical significance of the correlation between variables' Cronbach's alpha at the first and second measurement. Next, we checked whether there were significant differences between the baseline - follow-up group and the post-test follow-up group during the first measurement on demographic variables by conducting t-tests 
and chi-square tests. Moreover, to check whether students differed on socio-cognitive and behavioral variables at baseline, we performed a multivariate analysis of covariance (MANCOVA), with Gender and Education type as between-subjects (BS) variable and Social desirability as a covariate for the baseline - follow-up group during the first measurement $(\mathrm{N}=658)$.

To answer the first research question ('Is there an immediate effect of the program on socio-cognitive and behavioral variables?'), we performed a MANCOVA with data of the first measurement $(\mathrm{N}=1,362)$. In the MANCOVA, the socio-cognitive and behavioral variables served as dependent variables, with Group (i.e., Baseline - follow-up group and Post-test - follow-up group), Gender and Education type as BS variables and Social desirability as a covariate.

To answer the second research question ('Is there an effect of the program on sociocognitive and behavioral variables two months after session attendance?'), we conducted repeated measures MANCOVA with data of the baseline - follow-up group $(\mathrm{N}=136)$ with Measurement (i.e., First measurement and Second measurement) as within-subjects (WS) variable, Gender and Education type as BS variables and Social desirability as a covariate. Additional analyses were conducted to investigate the occurrence of a repeated questionnaire exposure effect. Finding no significant differences in the comparison of the follow-up measurements in both groups, but finding a significant difference between the baseline and post-test measurements indicates any effects found are attributable to the program rather than to repeated exposure to the questionnaire.

To answer the third research question ('Does the program have an immediate effect on participants' cognitive and emotional estate?'), we conducted univariate ANCOVA with Gender and Education type as BS variables and Social desirability as a covariate, separately for cognitive and emotional program impact.

To answer the fourth research question ('Does the program's immediate effect on participants' cognitive and emotional estate influence the program's impact on sociocognitive and behavioral variables?'), we divided participants into those scoring high and low on (cognitive/emotional) program impact, by means of a median split. We then conducted MANCOVA with Group (i.e., lower/higher program impact), Gender and Education Type as BS variables and Social desirability as a covariate, separately for cognitive and emotional program impact. For answering these last two research questions, we only used data from the first measurement in the Post-test - follow-up group ( $\mathrm{N}=704)$.

A Bonferroni correction served to control for Type 1 errors due to multiple testing (i.e., chance capitalization). The Greenhouse-Geisser epsilon correction factor was applied to compensate for possible effects of non-sphericity in the measurements compared. Only the corrected $\mathrm{F}$ and probability values are reported. An alpha level of .05 was maintained for all statistical tests. For the first two research questions, we reported effect sizes with Cohen's delta. A Cohen's delta of 0.2 indicates a small effect size, 0.5 indicates a medium effect size, and 0.8 indicates a large effect size.

\section{Results}

\subsection{Reliability analyses}

Since the Cronbach's alpha was sufficient for each variable (with the exception of Behavior in the baseline - follow-up group), scores on the separate items were averaged for the different variables. Test-retest reliability also proved to be sufficient (Table 1). 


\section{Table 1}

Reliability and mean scores for socio-cognitive and behavioral variables drawn from the Theory of Planned Behavior at time of and two months after session attendance to Traffic Informers in Belgian high school students, 2012-2013.

\begin{tabular}{|c|c|c|c|c|c|}
\hline Variables & $\begin{array}{l}\text { Cronbach's } \alpha \\
\text { First } \\
\text { measurement } \\
(\mathrm{N}=1,362) \\
\end{array}$ & $\begin{array}{l}\text { Cronbach's } \alpha \\
\text { Second } \\
\text { measurement } \\
(\mathrm{N}=136)\end{array}$ & $\begin{array}{l}\text { Test-retest } \\
\text { reliability } \\
(\mathrm{N}=136)\end{array}$ & $\begin{array}{l}\text { Mean (SD) } \\
\text { baseline - } \\
\text { follow-up group } \\
(\mathrm{N}=658)\end{array}$ & $\begin{array}{l}\text { Mean (SD) } \\
\text { post-test - } \\
\text { follow-up group } \\
(\mathrm{N}=704)\end{array}$ \\
\hline Attitude & .79 & .78 & $.70 * *$ & $2.32(0.44)$ & $2.28(0.43)$ \\
\hline Subjective norm & .66 & .73 & $.40 * *$ & $2.64(0.48)$ & $2.60(0.46)$ \\
\hline PBC & .70 & .69 & $.70 * *$ & $2.90(0.63)$ & $2.88(0.58)$ \\
\hline Behavioral intention & .69 & .70 & $.48 * *$ & $2.18(0.59)$ & $2.17(0.59)$ \\
\hline Behavior & .63 & .69 & $.56 * *$ & $2.24(0.55)$ & $2.22(0.52)$ \\
\hline Social desirability & .77 & .85 & $.65^{* *}$ & $2.43(0.65)$ & $2.45(0.61)$ \\
\hline Cognitive program impact & .90 & n.a. & n.a. & n.a. & $1.36(0.54)$ \\
\hline Emotional program impact & .78 & n.a. & n.a. & n.a. & $2.16(0.84)$ \\
\hline
\end{tabular}

\subsection{Group differences for the demographic variables}

Between the baseline - follow-up group and the post-test - follow-up group, there was a statistically significant difference on mean age, $t(1353.61)=2.93, p=.003$, with students in the post-test - follow-up group having a lower mean age (16.77 year) compared to students in the baseline - follow-up group (16.91 year). There was also a significant difference between the groups on Gender, $\chi^{2}(1, N=1358)=7.32, p=.007$, with more female students compared to male students in the baseline - follow-up group (55.50\%) and less female students compared to male students in the post-test - follow-up group (48.20\%). In addition, both groups significantly differed in terms of Education type, $\chi^{2}(2, N=1302)=8.78, p=.012$, with both groups consisting mostly out of students of technical education, followed by students of general and occupational education (Table 2).

\section{Table 2}

Mean scores and significance values at time of session attendance to Traffic Informers in Belgian high school students, 2012-2013.

\begin{tabular}{|c|c|c|c|}
\hline Demographic variable & $\begin{array}{l}\text { Mean (SD) } \\
\text { Baseline - follow-up group } \\
(\mathrm{N}=658)\end{array}$ & $\begin{array}{l}\text { Mean (SD) } \\
\text { Post-test - follow-up group } \\
(\mathrm{N}=704)\end{array}$ & p-value \\
\hline Age & $16.91(0.90)$ & $16.77(0.92)$ & $.003 * *$ \\
\hline Gender & Number $(\%)$ & Number $(\%)$ & $.007 * *$ \\
\hline Male & $292(44.40 \%)$ & $363(51.80 \%)$ & \\
\hline Female & $365(55.60 \%)$ & $338(48.20 \%)$ & \\
\hline Education type & Number $(\%)$ & Number $(\%)$ & $.012 *$ \\
\hline General education & $206(33.00 \%)$ & $205(30.20 \%)$ & \\
\hline Technical education & $227(36.40 \%)$ & $300(44.20 \%)$ & \\
\hline Occupational education & $191(30.60 \%)$ & $173(25.50 \%)$ & \\
\hline
\end{tabular}




\subsection{Baseline values for the socio-cognitive and behavioral variables}

Prior to session attendance, students were already quite road safety supportive (Table 1). We found a significant main effect of Gender, $F(5,572)=20.74, p=.00$ (Table 3). More specifically, for all socio-cognitive and behavioral variables (i.e., attitude, subjective norm, PBC, behavioral intention and behavior), female students, at baseline, are significantly more road safety supportive than male students $(\mathrm{p}<.001)$. In addition, there was a significant main effect of Education type, $\mathrm{F}(10,1144)=6.79, \mathrm{p}=.00$ (Table 3 ). With regard to attitude, behavioral intention and behavior, students of general and technical education, at baseline, are significantly more road safety supportive than students of occupational education $(p=.00)$. Turning to subjective norm, students of general education report, at baseline, a significantly more road safety supportive social environment than students of occupational education $(p=.01)$. There were no differences between the education types for PBC ( $p>.10)$.

\section{Table 3}

Mean scores for socio-cognitive and behavioral variables drawn from the Theory of Planned Behavior separately per gender and education type before session attendance to Traffic Informers in Belgian high school students, 2012-2013.

\begin{tabular}{|c|c|c|}
\hline Demographic variable & Socio-cognitive and behavioral variables & $\begin{array}{l}\text { Mean (SE) } \\
\text { Baseline - follow-up group } \\
(\mathrm{N}=658)\end{array}$ \\
\hline \multirow[t]{5}{*}{ Gender - female } & Attitude & $2.19(0.02)$ \\
\hline & Subjective norm & $2.59(0.02)$ \\
\hline & $\mathrm{PBC}$ & $2.75(0.03)$ \\
\hline & Behavioral intention & $2.06(0.03)$ \\
\hline & Behavior & $2.15(0.02)$ \\
\hline \multirow[t]{5}{*}{ Gender - male } & Attitude & $2.46(0.02)$ \\
\hline & Subjective norm & $2.70(0.02)$ \\
\hline & $\mathrm{PBC}$ & $3.08(0.03)$ \\
\hline & Behavioral intention & $2.34(0.03)$ \\
\hline & Behavior & $2.32(0.03)$ \\
\hline \multirow[t]{5}{*}{ Education - general } & Attitude & $2.25(0.03)$ \\
\hline & Subjective norm & $2.59(0.03)$ \\
\hline & $\mathrm{PBC}$ & $2.92(0.04)$ \\
\hline & Behavioral intention & $2.13(0.03)$ \\
\hline & Behavior & $2.14(0.03)$ \\
\hline \multirow[t]{5}{*}{ Education - technical } & Attitude & $2.27(0.03)$ \\
\hline & Subjective norm & $2.64(0.03)$ \\
\hline & PBC & $2.87(0.04)$ \\
\hline & Behavioral intention & $2.12(0.03)$ \\
\hline & Behavior & $2.20(0.03)$ \\
\hline Education - occupational & Attitude & $2.47(0.03)$ \\
\hline
\end{tabular}




$\begin{array}{ll}\text { Subjective norm } & 2.70(0.03) \\ \text { PBC } & 2.96(0.04) \\ \text { Behavioral intention } & 2.36(0.04) \\ \text { Behavior } & 2.37(0.03)\end{array}$

Note. Social desirability was entered as a covariate

\subsection{Research question 1: Is there an immediate effect of the program on socio-cognitive} and behavioral variables?

We found a significant interaction between Group and Education type, $\mathrm{F}(10,2416)=2.21$, $\mathrm{p}=.02$ (Table 4). More specifically, a significant program effect was established for students of general education, $\mathrm{F}(5,381)=3.26$, $\mathrm{p}=.01$, and occupational education, $\mathrm{F}(5,330)=3.96$, $\mathrm{p}=.00$, but not for students of technical education $\mathrm{F}(5,487)=1.18, \mathrm{p}=.32$. For students of general education, the program had an effect on all socio-cognitive variables (i.e., attitude, subjective norm, $\mathrm{PBC}$, and behavioral intention), but not on the behavioral variable (i.e., behavior), although this effect was marginally significant. For students of occupational education, the program had an effect on all socio-cognitive and behavioral variables (i.e., attitude, subjective norm, behavioral intention, and behavior), except for PBC, although this effect was marginally significant.

The significant program effects found for students of general and occupational education were small but positive with students being significantly more road safety supportive immediately after session attendance (i.e., at post-test) than prior to session attendance (i.e., at baseline). However, the effects for students of occupational education were smaller than the effects for students of general occupation.

\section{Table 4}

Mean scores, significance values and effect sizes for socio-cognitive and behavioral variables drawn from the Theory of Planned Behavior at time of session attendance to Traffic Informers in Belgian high school students of general and occupational education, 2012-2013.

\begin{tabular}{|c|c|c|c|c|c|}
\hline Education type & $\begin{array}{l}\text { Socio-cognitive and } \\
\text { behavioral variables }\end{array}$ & $\begin{array}{l}\text { Mean (SE) } \\
\text { Baseline - } \\
\text { follow-up group } \\
(\mathrm{N}=658)\end{array}$ & $\begin{array}{l}\text { Mean (SE) } \\
\text { Post-test - } \\
\text { follow-up } \\
\text { group } \\
(\mathrm{N}=704)\end{array}$ & p-value & Cohen's d \\
\hline \multirow[t]{5}{*}{ General education } & Attitude & $2.28(0.02)$ & $2.16(0.02)$ & $.00 * *$ & 0.40 \\
\hline & Subjective norm & $2.63(0.03)$ & $2.54(0.03)$ & $.02 *$ & 0.25 \\
\hline & PBC & $2.96(0.03)$ & $2.86(0.04)$ & $.03^{*}$ & 0.27 \\
\hline & Behavioral intention & $2.17(0.03)$ & $2.03(0.03)$ & $.00 * *$ & 0.38 \\
\hline & Behavior & $2.18(0.03)$ & $2.11(0.03)$ & .05 & n.a. \\
\hline \multirow[t]{5}{*}{ Occupational education } & Attitude & $2.45(0.03)$ & $2.30(0.03)$ & $.00 * *$ & 0.17 \\
\hline & Subjective norm & $2.68(0.04)$ & $2.53(0.04)$ & $.00 * *$ & 0.14 \\
\hline & PBC & $2.94(0.04)$ & $2.83(0.05)$ & .09 & n.a. \\
\hline & Behavioral intention & $2.34(0.04)$ & $2.14(0.04)$ & $.00 * *$ & 0.09 \\
\hline & Behavior & $2.35(0.04)$ & $2.22(0.04)$ & $.01 *$ & 0.01 \\
\hline
\end{tabular}

$* \mathrm{p}<.05 ; * * \mathrm{p}<.01 ;$ n.a. $=$ not applicable

Note. Social desirability was entered as a covariate 


\subsection{Research question 2: Is there an effect of the program on socio-cognitive and behavioral variables two months after session attendance?}

We found a significant interaction between Measurement and Gender, $F(5,94)=3.64$, $\mathrm{p}=.01$. More specifically, a significant program effect was established both for male students, $\mathrm{F}(5,27)=8.42, \mathrm{p}=.00$, and female students, $\mathrm{F}(5,62)=2.32, \mathrm{p}=.05$ (Table 5). For male students, the program had an effect on all socio-cognitive and behavioral variables (i.e., attitude, subjective norm, behavioral intention, and behavior), except for PBC, although this effect was marginally significant. For female students, the program only had an effect on PBC, although the program had marginally significant effects on behavioral intention and behavior.

The significant program effects found for male and female students were small to medium-sized but positive with students being significantly more road safety supportive two months after session attendance (i.e., at follow-up) than prior to session attendance (i.e., at baseline). However, the effects for female students were smaller than the effects for male students. Results of additional analyses indicate that it is unlikely that results for the program effect are confounded by a repeated questionnaire exposure effect.

\section{Table 5}

Mean scores, significance values and effect sizes for socio-cognitive and behavioral variables drawn from the Theory of Planned Behavior at time of and two months after session attendance to Traffic Informers in male and female Belgian high school students, 2012-2013.

\begin{tabular}{|c|c|c|c|c|c|}
\hline Gender & $\begin{array}{l}\text { Socio-cognitive and } \\
\text { behavioral variables }\end{array}$ & $\begin{array}{l}\text { Mean }(\mathrm{SE}) \\
\text { First } \\
\text { measurement } \\
(\mathrm{N}=658) \\
\end{array}$ & $\begin{array}{l}\text { Mean }(\mathrm{SE}) \\
\text { Second } \\
\text { measurement } \\
(\mathrm{N}=136)\end{array}$ & p-value & Cohen's d \\
\hline \multirow[t]{5}{*}{ Male } & Attitude & $2.45(0.08)$ & $2.29(0.08)$ & $.01 *$ & 0.34 \\
\hline & Subjective norm & $2.84(0.08)$ & $2.55(0.07)$ & $.00 * *$ & 0.56 \\
\hline & PBC & $3.01(0.11)$ & $2.87(0.10)$ & .06 & n.a. \\
\hline & Behavioral intention & $2.20(0.08)$ & $1.85(0.08)$ & $.00 * *$ & 0.55 \\
\hline & Behavior & $2.25(0.07)$ & $2.00(0.08)$ & $.00 * *$ & 0.34 \\
\hline \multirow[t]{5}{*}{ Female } & Attitude & $2.11(0.03)$ & $2.08(0.04)$ & .44 & n.a. \\
\hline & Subjective norm & $2.58(0.04)$ & $2.58(0.05)$ & .85 & n.a. \\
\hline & PBC & $2.70(0.07)$ & $2.54(0.06)$ & $.01 *$ & 0.30 \\
\hline & Behavioral intention & $1.94(0.05)$ & $1.82(0.05)$ & .06 & n.a. \\
\hline & Behavior & $2.04(0.05)$ & $1.93(0.05)$ & .05 & n.a. \\
\hline
\end{tabular}

$* \mathrm{p}<.05 ; * * \mathrm{p}<.01 ;$ n.a. $=$ not applicable

Note. Social desirability was entered as a covariate

\subsection{Research question 3: Does the program have an immediate effect on participants' cognitive and emotional estate?}

Students were both cognitively and emotionally affected by the program (Table 1). Paired samples t-test $(\mathrm{t}(597)=25.99, \mathrm{p}=.00)$ indicate that they were more cognitively $(\mathrm{M}=1.36$, $\mathrm{SD}=0.55)$ than emotionally affected $(\mathrm{M}=2.16, \mathrm{SD}=0.84)$ by the program. Furthermore, ANCOVA indicated that cognitive program impact differed in function of Gender $(\mathrm{F}(1,552)=30.36, \mathrm{p}=.00)$, with female students $(\mathrm{M}=1.23, \mathrm{SD}=0.03)$ significantly more affected 
by the program than male students $(\mathrm{M}=1.49, \mathrm{SD}=0.04, \mathrm{p}=.00)$. Cognitive program impact did not differ in function of Education type $(\mathrm{F}(2,552)=1.82, \mathrm{p}=.16)$. In addition, emotional program impact differed in function of gender $(\mathrm{F}(1,544)=19.76, \mathrm{p}=.00)$, with female students $(\mathrm{M}=2.00, \mathrm{SD}=0.05)$ significantly more affected by the program than male students $(\mathrm{M}=2.33$, $\mathrm{SD}=0.06, \mathrm{p}=.00)$. Emotional program impact also differed in function of Education type $(\mathrm{F}(2,544)=3.10, \mathrm{p}=.05)$. More in particular, students of occupational education $(\mathrm{M}=2.02$, $\mathrm{SD}=0.08)$ were emotionally marginally significantly more affected by the program than students of general education $(\mathrm{M}=2.25, \mathrm{SD}=0.06, \mathrm{p}=.06)$. Emotional program impact did not significantly differ between students of general and technical education $(\mathrm{p}=1.00)$.

\subsection{Research question 4: Does the program's immediate effect on participants' cognitive and emotional estate influence the program's impact on socio-cognitive and behavioral variables?}

Analyses based on median split (median cognitive program impact 1.00; median emotional program impact 2.00) revealed a significant main effect of group for both cognitive, $F(5,542)=4.73, p=.00$, and emotional program impact, $F(5,534)=5.10, p=.00$ (Table 6). Participants that were more cognitively and emotionally affected by the program were overall more road safety supportive compared to participants that were less cognitively and emotionally affected by the program.

\section{Table 6}

Mean scores and significance values for socio-cognitive and behavioral variables drawn from the Theory of Planned Behavior at time of session attendance to Traffic Informers in Belgian high school students in function of program impact (high vs. low), 2012-2013.

\begin{tabular}{|c|c|c|c|c|}
\hline Program impact & $\begin{array}{l}\text { Socio-cognitive and } \\
\text { behavioral variables }\end{array}$ & $\begin{array}{l}\text { Mean (SE) } \\
\text { Higher program } \\
\text { impact (group } 0 \text {, } \\
\mathrm{N}=311 \text { ) }\end{array}$ & $\begin{array}{l}\text { Mean (SE) } \\
\text { Lower program } \\
\text { impact (group 1, } \\
\mathrm{N}=248 \text { ) } \\
\end{array}$ & p-value \\
\hline \multirow[t]{5}{*}{ Cognitive } & Attitude & $2.22(0.02)$ & $2.34(0.02)$ & $.00 * *$ \\
\hline & Subjective norm & $2.57(0.03)$ & $2.66(0.03)$ & $.02 *$ \\
\hline & PBC & $2.81(0.03)$ & $2.93(0.03)$ & $.01 *$ \\
\hline & Behavioral intention & $2.07(0.03)$ & $2.26(0.03)$ & $.00 * *$ \\
\hline & Behavior & $2.17(0.03)$ & $2.29(0.03)$ & $.00 * *$ \\
\hline Program impact & $\begin{array}{l}\text { Socio-cognitive and } \\
\text { behavioral variables }\end{array}$ & $\begin{array}{l}\text { Mean (SE) } \\
\text { Higher program } \\
\text { impact (group 0, } \\
\mathrm{N}=287 \text { ) } \\
\end{array}$ & $\begin{array}{l}\text { Mean (SE) } \\
\text { Lower program } \\
\text { impact (group 1, } \\
\mathrm{N}=264 \text { ) } \\
\end{array}$ & p-value \\
\hline \multirow[t]{5}{*}{ Emotional } & Attitude & $2.22(0.02)$ & $2.33(0.02)$ & $.00 * *$ \\
\hline & Subjective norm & $2.59(0.03)$ & $2.67(0.03)$ & $.03 *$ \\
\hline & $\mathrm{PBC}$ & $2.84(0.03)$ & $2.92(0.03)$ & .06 \\
\hline & Behavioral intention & $2.07(0.03)$ & $2.29(0.03)$ & $.00 * *$ \\
\hline & Behavior & $2.18(0.03)$ & $2.32(0.03)$ & $.00 * *$ \\
\hline
\end{tabular}




\section{Discussion}

This study examined the effectiveness of a Flemish road safety program that uses testimonials by (relatives of) people who were involved in a traffic accident in order to stimulate $3^{\text {rd }}$ grade high school students to behave safely in traffic. In total, 1,362 students who were assigned to a baseline - follow-up group and a post-test - follow-up group participated to the study. Two demographic variables (i.e., gender and education type) were taken into account and we controlled for social desirability biases.

Immediately after attendance, the program had small but significant and positive effects on the socio-cognitive and behavioral variables (i.e., attitude, subjective norm, PBC, behavioral intentions and behavior). Interestingly, a more detailed analysis showed that these immediate program effects differed in function of education type. While students of general and occupational education were both significantly more road safety supportive after session attendance, no such effect could be established for students of technical education. As far as we know, there is no straightforward evidence for or insight into the more precise underlying reasons that might explain why in some cases students of a particular education type are significantly affected by road safety programs while others not. Therefore, we can only speculate about these reasons. One possible explanation for the significant program effect in the group of occupational education might be the fact that in this particular group, students held the least road safety supportive view at baseline (see Table 3), and thus, leaving a broader margin for the program to improve students' scores on the socio-cognitive and behavioral variables. Another possible explanation for the significant program effect in the group of occupational education might be the fact that in this particular group, students were significantly more emotionally affected by the program compared to students of general and technical education. Yet, these possible explanations for the significant program effect in the group of occupational education cannot explain the results found for the group of general education. No significant program effects were found in the group of technical education even when on the one hand, the majority of baseline values for students in technical education were not statistically different from those in the group of general education, and on the other hand, students in technical education were not significantly less affected by the program than students in general education. The possibility that the difference in program effectiveness between technical education on the one hand and general and occupational education on the other hand is to be attributed to a systematic difference in the way of bringing the testimonial sessions, is very unlikely because (a) the victims are all trained in standardizing as much as possible their testimonial style, (b) sometimes, a testimonial was brought in the different educational groups by the same victim, and (c) there is no reasonable argument to assume that testimonials would be brought the same way in groups of general and occupational education, while they would be brought differently in the group of technical education.

Two months after session attendance, there were significant, small to medium-sized positive effects on most of the socio-cognitive and behavioral variables. However, deviate from what we found for immediate program effects, the effects did not differ in function of education type anymore while they did differ in function of gender. That is, both male and female students were significantly more road safety supportive after session attendance. However, the program had more effect on males than on females. More specifically for males, the program had an effect on all socio-cognitive and behavioral variables, except for PBC, albeit this effect was marginally significant. For females, the program had an effect on PBC, although the program also had marginally significant effects on behavioral intention and behavior. These effects can be explained by the finding that male students held a less road safety supportive view than female students at baseline (see Table 3), thus leaving a broader margin for the program to improve students' scores on the socio-cognitive and behavioral 
variables. In contrast, female students scored higher on both cognitive and emotional program impact than male students. The finding that effects of road safety promoting programs can vary in function of gender is not surprising, and in line with previous research. For instance, King et al. (2008) examined the effectiveness of a road safety promoting program, and found more significant positive effects for females. Shinar and Compton (1995) examined the effectiveness of a road safety promoting program and indicated that the program might have the largest effect for males. The reason why a significant gender interaction occurred at the second measurement while no such interaction effect was found at the first measurement remains unclear. One would expect that an eventual gender interaction would occur rather at both the first and second measurement than at the second measurement only. Also, we have no direct explanation for the fact that there is no significant interaction anymore with education type at the second measurement.

Interestingly, the program had an immediate effect on participants' cognitive and emotional estate. More specifically, the program had more cognitive and emotional impact on female students than male students and more emotional impact on students of occupational education than students of general or technical education.

Finally, this study was the first to show that the impact of programs with victim testimonials on participants' cognitive and emotional estate is relevant for determining such programs' effect on the targeted socio-cognitive and behavioral variables. Interestingly, our results seem to suggest that, while there is enough support available in the literature for the finding that too high levels of cognitive/emotional arousal might result in counterproductive effects (e.g., Carey et al., 2013; Peters et al., 2012; Ruiter et al., 2001; Ruiter et al., 2014; Ruiter et al., 2004; Witte, 1992), too low levels of cognitive/emotional arousal should be avoided as well. Indeed, we found that less aroused participants became road safety supportive to a lesser extent than participants declaring they were more aroused by the program. Put together, these findings appear to be in line with the view that the relationship between stimulus arousal and message acceptance can best be represented as an inverted Ushaped curve with moderate arousal levels leading to optimal results (e.g., Janis, 1967; McGuire, 1968, 1969).

\section{Recommendations}

Based on the results of this study, we formulate the following three recommendations. First of all, victim testimonials have targeted a variety of road user populations. Originally, such testimonials were often meant to serve as a 'curative' or a 'corrective' measure for clinical use in adult road user populations with elevated risk-taking levels such as recidivists or occasional offenders. Gradually, the focus shifted to the use of such testimonials as a 'preventive' measure in the sensitization and education of students. Our study is in support of other work (i.e., King et al., 2008; Rosenbloom et al., 2009) indicating that personal testimonials by accident victims can stimulate high school students to reflect upon their participation in traffic in such a way they become more road safety supportive. Despite the fact that such positive effects have not been found in other studies (e.g., Feenstra et al., 2014; Glendon et al., 2014; Twisk et al., 2014), and that positive effects found are not always persistent over time (e.g., Poulter and McKenna, 2010), we think victim testimonials have increased influencing potential in high school student populations. We therefore recommend policy makers and practitioners considering the use of victim testimonials as a safety promoting strategy to focus more specifically on these age groups. Importantly, the effect of the program depends on characteristics of the student (i.e., education type, gender). This is in line with previous studies evaluating road safety campaigns among high school students 
(King et al., 2008; Rosenbloom et al., 2009; Ulleberg, 2002) and again illustrates that high school students are not a homogenous group. Therefore, different strategies are needed for the different subtypes of high school student to make them more road safety supportive.

Secondly, in line with already published work, this study shows that the effectiveness of victim testimonials is dependent upon several aspects related to how such testimonials are practically implemented. For example, while the objective of victim testimonials is to stimulate (self-) reflection by means of an emotional trigger (i.e., the personal testimonial of a traumatic experience), care must be taken of fact that the right emotions are being activated at the appropriate strength levels. As for the latter, we recommend practitioners to aim at moderate arousal levels since these can be expected to result in optimal message processing (e.g., Janis, 1967; McGuire, 1968, 1969). On the one hand, excessive emotional reactions can be prevented to a large extent already by avoiding too explicit emphasis on the immediate physical consequences of the accident itself. On the other hand, the risk of program participants not being or feeling engaged at all can be avoided by means of relatively simple arousal energizing strategies such as self-activation and social interaction.

Our third and final recommendation is based on a finding that resulted from item-level observation. There it came out that when generically formulated (i.e., stated in general rather than context-specific terms), participants' intentions to behave safely in traffic significantly increased after session attendance while this was not always the case when such behaviors were linked to a specific risk-facilitating or protection-inhibiting situation. For instance, while the intention to wear a safety helmet in general significantly improved after session attendance, the PBC to wear a safety helmet when accompanied by friends did not improve. In our opinion, this is an argument in support of the idea that victims when they bring their testimonial and reflect upon monitoring risks in traffic, should stay away as much as possible from vague and non-contextualized discourse. Otherwise, the risk remains that positively influenced general intentions will not translate into the desired behavior whenever participants are exposed to risk-facilitating or protection-inhibiting pressures. The creation of implementation plans might be a helpful technique to make sure that good behavioral intentions can result in the desired behavior. Such plans specify in detail the various steps that are needed to protect a person from the obstacles, frustrations, and temptations likely to be encountered, keeping in mind the demands of the current goal (i.e., to behave safely) that is being pursued (Gollwitzer, 1999). By designating a specific if-then contingency between an environment and a plan of action (i.e., if situation X arises, I will perform behavior Y), individuals construct a mental association between a specific situational cue and the appropriate goal-directed behavior response, e.g., 'when accompanied by friends, I will wear my safety helmet when bicycling' instead of 'I will wear my safety helmet' (Baumeister and Vohs, 2004). Research has indicated that this method is effective in translating behavioral intentions into behavior because it allows people to pass control over their behavior to the environmental cues contained in the implementation intention (Brewster et al., 2015; Sheeran and Orbell, 1999).

\section{Limitations and future research}

Unavoidably, this study has its limitations. Firstly, participants in this study were already quite road safety supportive prior to session attendance (see Table 1 and 3). This might have created a 'ceiling effect' in a sense that the margin available for the program to have an effect on participants' road safety supportive view was limited beforehand. Put differently, the results of this study in some way could be an underestimation of the program's true effectiveness. Relevant also in respect to an appropriate interpretation of the above 
mentioned, is to be precise enough in determining the program's true objective. For instance, while program developers position Traffic Informers as being aimed at the formation of a road safety supportive view, the alternative might be to state that the program's primary purpose is to positively reinforce favorable road safety supportive views that were already formed.

Secondly, the Traffic Informers program in its current format is a combination of a testimonial on the one hand, and an in-depth group discussion on the other hand. Our study has not examined what the impact is of each of these two program components. This is to a certain degree a limitation, more particularly for those practitioners who would be interested in finding out what the contribution of the different program components is like. Also, based on our study, we are unable to identify which specific aspects of the testimonial on the one hand, and of the group discussion on the other hand, do (or do not) work well.

Thirdly, even though a self-selection bias during the first measurement at the level of individual participants is not likely (i.e., inscription to the program was a decision taken at the school level, not at the individual student level), there still is a chance that such a bias occurred at the school level. Indeed, it could be the case that schools paying more attention to road safety were more motivated to inscribe to the program than schools paying less attention to road safety, creating an according bias in the data. A self-selection bias at the individual respondent level might however have occurred in the second measurement (i.e., two months after session attendance) in a sense that only those respondents truly caring about road safety were the ones motivated enough to fill out a questionnaire twice.

Finally, the external validity of this study is limited in different ways. For instance, the results apply only to programs adopting a comparable format. Also, our study results cannot be generalized to programs addressing different target populations than the one we addressed here. In addition, our study was conducted in high schools in Flanders only, so there is also a geographical restriction on the validity of our results.

Future research on the effectiveness of road safety interventions using victim testimonials to sensitize and educate high schools students is thus warranted. Such research could go in many directions. As a first avenue, it would be interesting to determine what the impact would be of the separate components (e.g., the personal testimonial and group discussion) within a combined program. Until now, the majority of evaluation studies have been carried out at the program overall level rather than adopting a component-specific perspective.

Furthermore, it would be valuable to know more precisely whether the inclusion of multiple victims within a single program generates any between-victim variability in the effectiveness of the program. Most program developers often foresee a (short duration) training of the victims before they go out to bring their stories. These training sessions are not only aimed at practicing certain skills and raising victims' self-confidence, but also serve to somewhat standardize the program format. It is still unclear whether (and to what extent) these sessions reach that objective.

Moreover, it would be insightful to examine whether embedding victim testimonials into a multi-delivery program format (e.g., Elkington, 2005) with pre- and follow-up sessions to foster the key-messages raised and discussed during the testimonial sessions, enhances the impact of victim testimonials.

Finally, we think the inclusion of other variables (e.g., implementation intentions) than the ones included in this study could be useful to learn what are the potential purposes for which policy makers can use victim testimonials. 


\section{Acknowledgements}

This study was funded by the Policy Research Center for Traffic Safety. The authors thank the non-profit organization Rondpunt and the high schools in Flanders for their cooperation. The authors also thank Helmut Paris for his advice on the questionnaire and Robert A.C. Ruiter for his useful comments on a prior draft of this paper.

\section{References}

Af Wåhlberg, A.E., 2009. Driver behaviour and accident research methodology: Unresolved problems. Ashgate.

Ajzen, I., 1985. From intentions to actions: a theory of planned behavior. In: Kuhl, J., Beckmann, J. (Eds.), Action Control: From Cognition to Behavior. Springer-Verlag, Berlin

Baumeister, R. F., Vohs, K.D., 2004. Handbook of self-regulation. Research, Theory, and Applications. The Guilford Pres, New York.

Brewster, S.E., Elliot, M.A., Kelly, S.W., 2015. Evidence that implementation intentions reduce drivers' speeding behavior: Testing a new intervention to change driver behavior. Accident Analysis and Prevention 74, 229-242.

Brijs, K., Cuenen, A., Brijs, T., Ruiter, R.A.C., Wets, G., 2014. Evaluating the effectiveness of a post-license education program for young novice drivers in Belgium. Accident Analysis and Prevention 66, 62-71.

Carey, R.N., McDermott, D.T., Sarma, K.M., 2013. The impact of threat appeals on fear arousal and driver behavior: a meta-analysis of experimental research 1990-2011. PLOS One 8 (5), 1-8.

Conner, M., Lawton, R., Parker, D., Chorlton, K., Manstead, A.S.R., Stradling, S., 2007. Application of the theory of planned behaviour to the prediction of objectively assessed breaking of posted speed limits. British Journal of Psychology 98, 429-453.

Elkington, J., 2005. Evaluation of the RYDA road safety education program. In: Paper Presented at the Annual Conference of the Institute of Public Works Engineering Australia NSW Division, NSW, Australia.

Elliott, M.A., Armitage, C.J., Baughan, C.J., 2007. Using the theory of planned behaviour to predict observed driving behaviour. British Journal of Social Psychology 46, 69-90.

Elliott, M.A., Thomson, J.A., Robertson, K., Stephenson, C., Wicks, J., 2013. Evidence that changes in social cognitions predict changes in self-reported driver behavior: Causal analyses of two-wave panel data. Accident Analysis and Prevention 50, 905-916.

Feenstra, H., Ruiter, R.A.C., Kok, G., 2014. Evaluating traffic informers: Testing the behavioral and social-cognitive effects of an adolescent bicycle safety education program. Accident Analysis and Prevention 73, 288-295.

Field, A., 2013. Discovering Statistics Using IBM SPSS Statistics, fourth ed. Sage Publications Ltd., London, UK.

Glendon, A.I., McNally, B., Jarvis, A., Chalmers, S.L., Salisbury, R.L., 2014. Evaluating a novice driver and pre-driver road safety intervention. Accident Analysis and Prevention 64, 100-110.

Godin, G., Kok, G., 1996. The theory of planned behavior: a review of its applications to health-related behaviors. American Journal of Health Promotion 11, 87-98.

Gollwitzer, P. M., 1999. Implementation intentions: Strong effects of simple plans. American Psychologist 54, 493-503. 
Harrison, W.A., 2010. Is it finally time to kill self-report outcome measures in road safety? An investigation of common method variance in three surveys of a cohort of young drivers that included the Driver Behavior Questionnaire. Paper presented at the Australian Road Safety, Research, Policing and Education Conference, Canberra.

Janis, I.L., 1967. Effects of fear arousal on attitude change: Recent developments in theory and experimental research. In L. Berkowitz (Ed.), Advances in experimental social psychology (Vol. 3, pp. 166-225). New York: Academic Press.

King, K.A., Vidourek, R.A., Love, J., Wegley, S., Alles-White, M., 2008. Teaching adolescents safe driving and passenger behaviors: Effectiveness of the You Hold They Key Teen Driving Countermeasure. Journal of safety research 39, 19-24.

Lajunen, T., Corry, A., Summala, H., Hartley, L., 1997. Impression management and selfdeception in traffic behaviour inventories. Person. Individ. Diff. 22(3), 341-353.

Lajunen, T., Özkan, T., 2011. Chapter 4: Self-report instruments and methods. In: B.E. Porter (Eds.), Handbook of Traffic Psychology (pp. 43-60). USA:Elsevier.

Linderholm, I. B., 2000. Drink and drive. Can media campaigns solve the problem? Proceedings of ICADTS Conference 2000, Stockholm, Sweden.

McGuire, W.J., 1968. Personality and susceptibility to social influence. in E. Borgatta and W. Lambert (Eds.), Handbook of personality theory and research(pp. 1130-1187). Chicago: Rand McNally.

McGuire, W.J., 1969. The nature of attitudes and attitude change. In G. Lindzey and E. Aronson (Eds.), The handbook of social psychology (Vol. 3, pp. 136-314). Reading, MA: Addison-Wesley.

Moan, I.S., Ulleberg, P., 2007. Evaluation of the traffic safety measure: "Being Dead Isn't Cool". Norwegian Center for Transport Research (TOI). Report 872-2007.

O'Brien, G., Rooney, F., Carey, C., Fuller, R., 2002. Evaluation of the effectiveness of a dramatic presentation on attitudes to road safety. In: Department for Transport, ed. Behavioural research in road safety: twelfth seminar.

Paulhus, D. L. 1984. Two-components models of socially desirable responding. Journal of Personality and Social Psychology 15, 383-388.

Paulhus, D. L., Reid, D. B., 1991. Enhancement and denial in socially desirable responding. Journal of Personality and Social Psychology 60, 307-317.

Peters, G.J.Y., Ruiter, R.A.C., Kok, G., 2012. Threatening communication: a critical reanalysis and a revised meta-analytic test of fear appeal theory. Health Psychology Review, $1-24$.

Pfeiffer, R., Taubert, L., Walk, M., Reutter, U., Knauer-Lukas, M., Seda, E., StelmachowiczPawyza, D., Linderholm, I., 2006. Close-To EU final report.

Polacsek, M., Rogers, E.M., Woodall, W.G., Delaney, H., Wheeler, D., Rao, N., 2001. MADD Victim Impact Panels and Stages-of-Change in Drunk-Driving Prevention. J. Stud. Alcohol 62, 344-350

Poulter, D.R., McKenna, F.P., 2010. Evaluating the effectiveness of a road safety education intervention for pre-drivers: An application of the Theory of Planned Behavior. British Journal of Educational Psychology 80, 163-184.

Powney, J., Glissov, P., Hall, S., 1995. The use of theatre tours in road safety education. Drinking, driving and young people. Edinburgh: Scottish Council for Research in Education (SCRE). Research Report No. 66.

Rosenbloom, T., Levi, S., Peleg, A., Nemrodov, D., 2009. Effectiveness of road safety workshop for young adults. Safety Science 47, 608-613.

Ruiter, R.A.C., Kessels, L.T.E., Peters, G-J.Y., Kok, G., 2014. Sixty years of fear appeal research: Current state of the evidence. International Journal of Psychology 49(2), 63-70. 
Ruiter, R. A. C., Abraham, C., Kok, G., 2001. Scary warnings and rational precautions: A review of the psychology of fear appeals. Psychology and Health 16, 613-630.

Ruiter, R.A.C., Verplanken, B., De Cremer, D., Kok, G., 2004. Danger control and fear control in response to fear appeals: the role of need for cognition. Basic and Applied Social Psychology 26, 13-24.

Shadish, W.R., Cook, T.D., Campbell, D.T., 2002. Experimental and quasi-experimental designs for generalized causal inference. Wadsworth, Cengage Learning, USA.

Sheeran, P., Orbell, S., 1999. Implementation intentions and repeated behaviour: augmenting the predictive value of the theory of planned behavior. European Journal of Social Psychology 29, 349-369.

Shinar, D., Compton, R.P., 1995. Victim Impact Panels: Their impact on DWI recidivism. Alcohol, drugs and driving 11(1), 73-87.

Stutton, S., 1998. Predicting and explaining intentions and behavior: how well are we doing? Journal of Applied Social Psychology 28, 1317-1338.

Twisk, D.A.M., Vlakveld, W.P., Commandeur, J.J.F., Shope, J.T., Kok, G., 2014. Five road safety education programmes for young adolescent pedestrians and cyclists: A multiprogramme evaluation in a field setting. Accident Analysis and Prevention 66, 55-61.

Ulleberg, P., 2002. Personality subtypes of young drivers. Relationship to risk-taking preferences, accident involvement, and response to a traffic safety campaign. Transportation Research Part F 4, 279-297.

Witte, K., 1992. Putting the fear back into fear appeal: the extended parallel process model. Communication Monographs 59, 329-349. 